\title{
Skapulada Yerleşen Tümör ve Tümör Benzeri Lezyonlara Genel Bakış; Bir Üniversite Hastanesinin Deneyimi
}

\author{
Ali Erkan YENİGÜL, Mühammet Sadık BİLGEN \\ Bursa Uludağ Üniversitesi Tıp Fakültesi, Ortopedi ve Travmatoloji Anabilim Dalı, Bursa.
}

ÖZET

Çalıșmamızda skapula yerleșimli ve histopatolojik olarak tanısı kesinleşmiş tümör veya tümör benzeri lezyonları, bunların tedavi ve takip sonuçlarını inceledik. Böylece nadir görülen bu lezyonların tanı dağılımını ve tedavi sonuçlarını değerlendirerek literatüre katkı sağlamayı amaçladık. 2015-2020 yılları arasında histopatolojik tanı alan skapula yerleşimli lezyonu olan olguları ve bu olguların yaş, cinsiyet, semptom, semptom süresi, kitle lokalizasyonu patolojik kırk olup olmaması (tanı esnasında), tedavi şekli (biyopsi, cerrahi, kemoterapi, radyoterapi), tedavi sonrası komplikasyon ve tanı anından itibaren takip süreleri incelendi. Çalışmaya 21 erkek, 8 kadın olmak üzere 29 olgu katıldı. Yaş ortalaması 50 (11-84) idi. 17 olguda sol skapulada lezyon var iken 12 olguda sağ skapulada lezyon vardı. 21 olgu ağrı şikayeti ile, 5 olgu şişlik şikayeti ile ve 3 olguda ağrı+şişlik şikayeti ile başvurmuştu. Olgulardan tanı öncesi semptom bulunma süresi ortalama 6 ay (1-15)'dı. 12 olguda benign lezyon var iken 17 olguda malign lezyon vardı. 9 olguda metastaz nedenli malignite var iken 8 olguda primer malignite vard1. Lezyon yerleşimleri 4 olguda sadece S1, 12 olguda sadece S2 ve 13 olguda S1+S2 bölgelerinde idi. Ortalama takip süresi 33 ay (6-64) olup, takip esnasında 5 olgu ex olmuştur. Skapulada tümör ve tümör benzeri lezyonlara baktı̆̆ımızda malignitelerin fazla olduğu görülmektedir. Olgu yaşı arttıkça benignden maligne doğru da bir artış var. Radyolojik olarak detaylı araştırılması gereken bu lezyonlar histopatolojik inceleme sonrası başarılı şekilde tedavi edilebilmektedir.

Anahtar Kelimeler: Skapula. Histopatoloji. Tümör. Tümör benzeri.

Overview of Tumors and Tumor-Like Lesions Located in The Scapula: Experience of an University Hospital

\begin{abstract}
In our study, we examined tumors or tumor-like lesions located in the scapula and diagnosed them histopathologically, and their treatment and follow-up results. Thus, we aimed to contribute to the literature by evaluating the diagnosis distribution and treatment results of these rare lesions. Cases with scapula-located lesion who were diagnosed histopathologically between 2015-2020 were determined. The age, gender, symptoms, duration of symptoms, mass localization, pathological 40 (during diagnosis), treatment type (biopsy, surgery, chemotherapy, radiotherapy), post-treatment complications and follow-up times from the diagnosis were examined. Of the 29 cases included in the study, 21 were male and 8 were female. The mean age was $50(11-84)$. While 17 patients had a lesion in the left scapula, 12 patients had a lesion in the right scapula. 21 cases presented with the complaint of pain, 5 cases with the complaint of swelling, and 3 cases with the complaint of pain+swelling. The mean duration of symptoms before diagnosis was 6 months (1-15). While 12 cases had benign lesions, 17 cases had malignant lesions. While 9 cases had malignancy due to metastasis, 8 cases had primary malignancy. The lesion localizations were only $\mathrm{S} 1$ in 4 cases, S2 only in 12 cases, and S1+S2 in 13 cases. The mean follow-up period was 33 months (6-64), and 5 cases died during the follow-up. When we look at tumors and tumor-like lesions in the scapula, it is seen that malignancies are high. As the age of the case increases, there is an increase from benign to malignant. These lesions, which need to be investigated in detail radiologically, can be successfully treated after histopathological examination.
\end{abstract}

Key Words: Scapula. Histopathologically. Tumor. Tumor-like.

Gelis Tarihi: 24.Ağustos.2021

Kabul Tarihi: 18.Kasım.2021

Dr. Ali Erkan YENIGÜL

Bursa Uludağ Üniversitesi Tıp Fakültesi,

Ortopedi ve Travmatoloji Anabilim Dalı,

Bursa.

Tel: 05058254619

E-posta: alierkanyenigul@uludag.edu.tr

Yazarların ORCID Bilgileri:

Ali Erkan YENIGÜL: 0000-0002-2690-9488.

Mühammet Sadık BiLGEN: 0000-0003-2415-9529.
Literatürde 'Omuz kuşağı' olarak belirtilen bölgenin bir parçası olan skapulanın izole lezyonları nadir görülmektedir. Skapulanın patolojik tutulumları da primer kemik tümörlerinden hematolojik malignitelere, metastazlardan tümör benzeri benign lezyonlara kadar geniş bir tanı dağılımı göstermektedir ${ }^{1}$. Literatürdeki çalışmalar, skapuladaki primer kemik tümörlerinin benign olmaktan çok malign olma olasılığının daha yüksek olduğunu göstermiştir ${ }^{2-4}$. Skapulada yaygın görülen benign tümörler osteokondrom, osteoid osteom iken malign tümörler metastazlar, kondrosarkom ve osteosarkomlardir ${ }^{5}$. 
Skapulada tanı alan benign lezyonlar ameliyatsız takip edilebilirken, malign tutulumlar genelde eksize edilmektedir. Skapula tümörlerinde erken tanı konulabilmesi tedavi başarısında etkilidir. Fakat bu bölgedeki tanı çeşitliliğinin fazla olması, tümörlerin nadir görülmesi ve semptomlarının az olması bu durumu zorlaştırmaktadır ${ }^{4,6}$. Özellikle bu bölgenin tümörlerini konu alan makaleler çok azdır. Bu yüzden çalışmamızda skapula yerleşimli ve histopatolojik olarak tanısı kesinleşmiş tümör veya tümör benzeri lezyonları, bunların tedavi ve takip sonuçlarını inceledik. Böylece nadir görülen bu lezyonların tanı dağılımını ve tedavi sonuçlarını değerlendirerek literatüre katkı sağlamayı amaçladik.

\section{Gereç ve Yöntem}

Çalışma Ocak 2015- Aralık 2020 tarihleri arasında kliniğimizde skapulada tümör veya tümör benzeri lezyonlar nedeniyle tedavi almış olgular dahil edildi. Etik kurul onayı üniversitesimiz Etik Kurulunda 202110/21 sayılı kararı ile kayıtlıdır. Çalışma, Helsinki Beyannamesi'nde belirtilen etik ilkelere uygun olarak yürütüldü.

Çalışmaya en az 6 aylık takip sonuçları olan skapula yerleşimli lezyonlardan histopatolojik tanıları olan olgular dahil edildi. Olguların tanı ve tedavi aşamaları üniversitemizdeki multidisipliner kas iskelet sistemi tümör konseyi tarafindan değerlendirme ile yönetildi. Kemik uzantısı olmayan çevre yumuşak doku tümörleri ile histopatolojik olarak tanısı kesinleştirilememiş olgular ekarte edildi.

Çalışmaya kriterleri karşılayan toplam 29 olgu dahil edildi. Tüm olguların yaş, cinsiyet, semptom, semptom süresi, omuz eklem hareketleri, kitle lokalizasyonu patolojik kırk olup olmaması (tanı esnasında), tedavi şekli (biyopsi, cerrahi, kemoterapi, radyoterapi), tedavi sonrası komplikasyon ve tanı anından itibaren takip süreleri incelendi.

Musculoskeletal Tumor Society (MSTS), omuz kuşağ 1 tümörleri için skapulayı iki bölgeye ayıran bir sınıflandırma sistemi geliştirmiştir ${ }^{7}$ : spina skapula-skapula gövdesi S1 olarak adlandırılır iken akromion -glenoid kompleksi S2 olarak adlandırılmıştır. Bu sınıflandırma fonksiyonel değerlendirmeler ve rekonstrüksiyon seçiminde de önem arzetmektedir ${ }^{1}$. Omuz eklem hareketleri normalde elevasyon $120^{\circ}$, ekstansiyon $45^{\circ}$, abduksiyon $130^{\circ}$, internal rotasyon $45^{\circ}$ ve eksternal rotasyon $120^{\circ}$ 'dir. Muayenede bu değerlerin birinde $\% 50$ oranında veya birden fazlasında $\% 25$ oranında kısitlanma var ise sinırlı omuz eklem hareketi olarak değerlendirildi.

Tablo I. Olgular ve klinik özellikleri

\begin{tabular}{|c|c|c|c|c|c|c|c|c|}
\hline Olgu & Cinsiyet & Yas & Tanı & Taraf & Şlkayet & Lokalizasyon & Tedavi & Takip(ay) \\
\hline 1 & E & 16 & OSTEOKONDROM & $\mathrm{SOL}$ & ŞIŞLIKK & S2 & EKSIZYON & 64 \\
\hline 2 & $\mathrm{~K}$ & 57 & KONDROSARKOM & SAĞ & AĞRI+ŞIŞLIKK & $\mathrm{S} 1+\mathrm{S} 2$ & AMPUTASYON & 48 \\
\hline 3 & $E$ & 84 & METASTAZ ADENOKARSINOM & SOL & AĞRI & S1 & KT & 22 \\
\hline 4 & $E$ & 35 & ENKONDROM & SOL & AĞRI & S2 & EKSIZYON & 57 \\
\hline 5 & $E$ & 30 & ANEVRIZMAL KEMIK KISTi & SOL & AĞRI & S2 & KÜRETAJ GREFTLEME & 55 \\
\hline 6 & $\mathrm{~K}$ & 52 & METASTATIK MEME KARSINOM & SAĞ & AĞRI & S2 & KT-RT & 27 \\
\hline 7 & $E$ & 49 & NÜKS SINOVIAL SARKOM & SOL & ŞIŞLIIK & $\mathrm{S} 1+\mathrm{S} 2$ & KT-RT, AMPUTASYON & 25 \\
\hline 8 & $E$ & 62 & METASTAZ MIDE KARSINOM & SAĞ & AĞRI & S2 & KT-RT & 68 \\
\hline 9 & $E$ & 73 & METASTAZ KARSINOMA & SAĞ & AĞRI & S2 & KT & 16 \\
\hline 10 & $E$ & & $\begin{array}{l}\text { LANGERHANS HÜCRELI } \\
\text { HISTIYOSITOZ }\end{array}$ & SOL & AĞRI & S2 & KT-RT & 13 \\
\hline 11 & $E$ & 14 & EOZINOFILIK GRANÜLOMA & SAĞ & AĞRI & S1 & TAKIP & 44 \\
\hline 12 & K & 43 & METASTAZ AKCIGGER KARSINOM & SOL & AĞRI & S2 & KT & 51 \\
\hline 13 & $E$ & 56 & PLEOMORFIK HÜCRELI SARKOMA & SAĞ & ŞIŞLIKK & S1+S2 & KT, AMPUTASYON & 19 \\
\hline 14 & $E$ & 18 & EOZINOFILIK GRANÜLOMA & SOL & AĞRI & $\mathrm{S} 1+\mathrm{S} 2$ & TAKIP & 33 \\
\hline 15 & $E$ & 84 & SKLEROTIK KEMIK TRABEKÜLLERI & SOL & AĞRI & S2 & TAKIP & 20 \\
\hline 16 & $E$ & 71 & TELENJIEKTATIKK OSTEOSARKOMA & SOL & AĞRI & $\mathrm{S} 1+\mathrm{S} 2$ & KT-RT+AMPUTASYON & 45 \\
\hline 17 & $E$ & 56 & SINOVIAL SARKOM & SAĞ & ŞIŞLIKK & $\mathrm{S} 1+\mathrm{S} 2$ & EKSIZYON & 18 \\
\hline 18 & E & 67 & PLAZMA HÜCRELİ MYELOMA & SOL & AĞRI & S1+S2 & KT-RT & 48 \\
\hline 19 & $E$ & & $\begin{array}{l}\text { NÜKS PLEOMORFIK HÜCRELİ } \\
\text { SARKOMA }\end{array}$ & SAĞ & AĞRI-ŞIŞLİK & $\mathrm{S} 1+\mathrm{S} 2$ & $\begin{array}{l}\text { KT, RT, AMPUTASYON- } 6 \\
\text { AY-EKSIZYON }\end{array}$ & 24 \\
\hline 20 & K & & SOLITARY FIBRÖZ TÜMÖR & SOL & AĞRI & S2 & TAKIP & 15 \\
\hline 21 & $E$ & & INTRAOSSEÖZ LIPOM & SOL & ŞIŞLIKK & $\mathrm{S} 1+\mathrm{S} 2$ & EKSIZYON & 41 \\
\hline 22 & K & & KONDROSARKOM & SOL & AĞRI & S1 & AMPUTASYON & 9 \\
\hline 23 & K & & METASTAZ KARSINOMA & SOL & AĞRI & $\mathrm{S} 1+\mathrm{S} 2$ & KT-RT & 16 \\
\hline 24 & $E$ & 53 & METASTAZ ADENOKARSINOM & SAĞ & ŞIŞLIK+AĞRI & $\mathrm{S} 1+\mathrm{S} 2$ & $\mathrm{KT}+\mathrm{RT}$ & 19 \\
\hline 25 & K & & OSTEOKONDROM & SAĞ & AĞRI & S1 & EKSIZYON & 50 \\
\hline 26 & $E$ & & OSTEOKONDROM & SOL & AĞRI & S2 & EKSIZYON & 37 \\
\hline 27 & K & & $\begin{array}{l}\text { METASTAZ RENAL HÜCRELİ } \\
\text { KARSINOM }\end{array}$ & SAĞ & AĞRI & $\mathrm{S} 1+\mathrm{S} 2$ & KT-RT & 6 \\
\hline 28 & $E$ & & DESMOPLASTIC FIBROMA & SOL & AĞRI & $\mathrm{S} 1+\mathrm{S} 2$ & TAKIP & 61 \\
\hline 29 & $E$ & & METASTAZ MIDE KARSINOM & SAĞ & AĞRI & S2 & KT & 18 \\
\hline
\end{tabular}

KT: Kemoterapi, RT: Radyoterapi, S1: spina skapula-skapula gövdesi, S2: akromion -glenoid kompleksi 


\section{Bulgular}

Çalışma kriterlerine uyan skapula yerleşimli 29 olgunun 21'i erkek, 8'i kadındı ve çalışma grubunun yaş ortalamas1 50 idi. 17 olguda sol skapulada lezyon var iken 12 olguda sağ skapulada lezyon vardı. $21 \mathrm{olgu}$ ağrı şikayetiyle, 5 olgu şişlik şikayetiyle ve 3 olguda ağrı ve şişlik şikayeti ile başvurdu. Olgulardan tanı öncesi semptom bulunma süresi ortalama 6 ay (115)'d1. 12 olguda benign lezyon var iken 17 olguda malign lezyon vardı. 9 olguda metastaz nedenli malignlite var iken 8 olguda primer malignite vard1. Olguların tanı ve klinik özellikleri Tablo I'de gösterilmiştir.

Çalışma grubundaki 23 olguda biyopsi yapılırken 6 olguya kitle eksizyonu uyguland1. Malignite tanılı 6 olguya fourquarter ampütasyon (interskapulotorasik ampütasyon), 5 olguya kemoterapi ve radyoterapi, 4 olguya ise sadece kemoterapi uyguland. Sinovial sarkom tanılı bir olguya eksizyon uyguland1. Anevrizmal kemik kisti tanılı olguya küretaj ve greftleme cerrahisi yapıldı. Nüks tanısı alan sinovial sarkomlu olguda ilk ameliyatta geniş cerrahi rezeksiyon uygulanmış sonrasında ampütasyon yapıldı. Pleomorfik hücreli sarkom tanılı olguda ilk ameliyatta ampütasyon yapılan hastada lokal nüks görüldü ve geniş cerrahi rezeksiyon uygulandı (Resim 1). Olguların başvurularında veya takiplerinde patolojik kırık görülmedi. Ortalama takip süresi 33 ay (6-64) olup, takip esnasinda 5 olgu ex olmuştur.

\section{Tartışma}

Çalışma grubumuzda malign tanı alan olguların say1larının benign tanılarda fazladır ve bu sonuç literatür ile uyumludur. Çalışmamızda en sık görülen primer kemik tümörü kondrosarkomdu. Yine literatüre benzer şekilde en yaygın görülen yumuşak doku sarkomlarının, daha önce malign fibröz histiositoma (MFH) olarak adlandırılan yüksek dereceli farklılaşmamış pleomorfik sarkom olduğunu gösterdik.

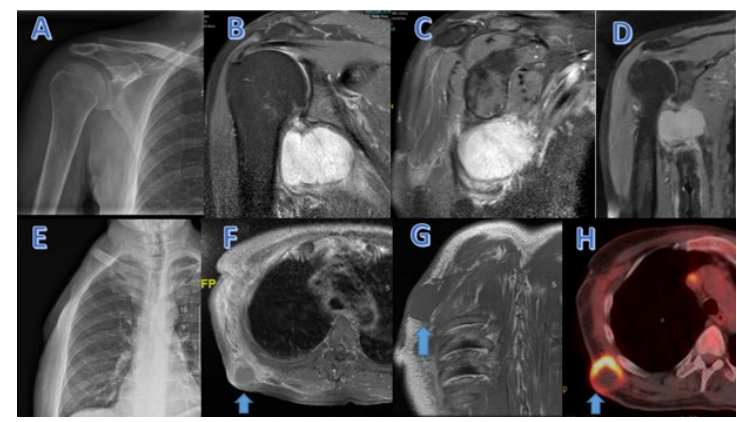

Sekil 1:

52 yaş erkek olgu. A,B,C ve D kesitlerinde Pleomorfik Sarkom mevcut. C kesiti ampütasyon sonrası röntgenogram. F, $G$ ve H kesitleri ampütasyondan 6 ay sonra görülen lokal nüks. Geniş cerrahi sınırlar ile eksize edildi.

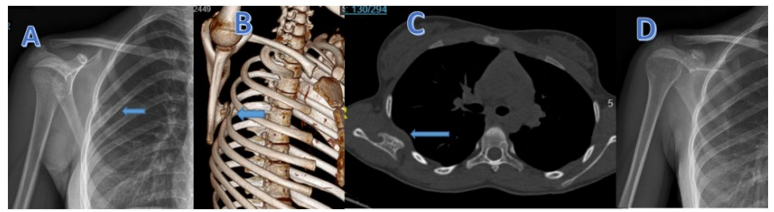

Şekil 2:

A,B,C kesitlerinde sağ skapula kostal yüzde osteokondrom ile uyumlu görüntü. D kesitinde eksizyonel biyopsi sonrasi kontrol grafi.

Skapulada en sık tanı alan benign kemik lezyonu osteokondromdur ve genellikle ilk dört dekatta tanı almaktadır. (Resim: 2 Örnek osteokondrom vakası) Çalışmamizda 3 olguda osteokondrom vard1 ve hastalar gençti. Skapulada metastaz tanısı alan 3 olguda primer tanı yoktu ve skapula metastazı sonrası primer tanıları araştırıldı. Çalışmamızda yaş dağılımlarına baktığ1mızda orta ve ileri yaş dönemindeki hastaların gençlerden fazla olduğu görülmektedir. Khan ve arkadaşlar1 da skapula lezyonlarının altıncı deketta arttığını rapor etmişlerdir ${ }^{8}$. İleri yaşlarda malign tanılar artar iken genç yaşlarda benign tanılar ön planda görülmektedir ${ }^{5}$.

Skapuladaki tümörler diğer anatomik bölgelerdekilere benzer şekilde davranabilirken, teşhisin gecikmesi nedeniyle tedavi genellikle hastalığın ilerlemesinde daha sonraki bir noktada başlatılır ${ }^{6}$. Skapulayı çevreleyen kas yapısı nedeniyle, tümör oldukça büyüyene kadar bir kitle genellikle palpe edilemez ${ }^{5}$. Radyolojik değerlendirme ile tüm skapula tümörleri tanı alamamaktadır. Hatta malign ve benign ayrımı için bile radyoloji yetersiz kalabilmektedir. Kemik dokuda yıkıcı lezyonlar sıklıkla maligndir, ancak kondrosarkom gibi bazı malign lezyonlar mikst veya sklerotik patern gösterebilir ${ }^{9}$. İleri yaşlarda ve skapulada yaygın tutulumu olan lezyonlarda malignite ihtimali artmaktadır. Kesin tanı için biyopsi veya eksizyon gerekmektedir. Skapulada tanı koymak için biyopsi çok kıymetli olduğu gibi skapulanın anatomik yerleşiminden dolayı da bir o kadar zordur. Biyopsi esnasında nörovasküler yapılar korunmalı, invazif olmayan yumuşak dokulara kontaminasyondan kaçınılmalı ve göğüs duvarı yaralanması önlenmelidir ${ }^{10}$. Bizim çalışmamızda da hastaların tümünden histopatolojik inceleme yapılmıştır. Hastaların 23'üne biyopsi, 6'sına eksizyonel biyopsi uyguladık. Biyopsiler esnasında herhangi bir komplikasyon gelişmedi.

Skapulada nörovasküler yapılar etrafında çalışmanın zorluğu nedeniyle çoğu zaman ampütasyon büyük omuz tümörleri için tercih edilmektedir ${ }^{11,12}$. Cerrahi tekniklerin, görüntülemenin ve neoadjuvan tedavilerin ilerlemesiyle, uzuv kurtarma cerrahileri alternatif bir tedavi halini ald $1^{10,13}$. Skapulada kitle eksizyonu uygulanacağı zamanda cerrahi sınırlar kitlenin tanısına ve yayılımına göre belirlenir ${ }^{5}$. Çalışma grubumuzda yer aldığı üzere Anevrizmal kemik kisti tanılı hastaya küretaj ve graftleme, osteokondrom tanılı hastada 
sadece eksizyon, eozinofilik granülom tanılı hastada takip tedavisi uyguland. Uzuv kurtarma cerrahisi için kontraendikasyonlar; nörovasküler yapıların invazyonu, kitlenin omuz kuşağının distaline kadar uzanması, biyopsi alanı nedenli geniş kontaminasyonlar sayılabi$\operatorname{lir}^{10}$. Bizim çalışmamızda da bu kontraendikasyonlar ve geniş tümör tutulumları nedeniyle altı hastaya fourguarter ampütasyon uygulandı. Ayrıca çalışmamızda görüldüğü üzere; geniş cerrahi eksizyon sonrası nüks nedenli ampütasyon yapıldığı gibi, ampütasyon sonrası nüks nedenli geniş cerrahi eksizyon yapılmak durumunda da kalınabilinir.

Çalışmamızda az sayıda vakanın görüldüğü lokalizasyonlardaki tümör sonuçlarının klinikler tarafından paylaşılması, literatürdeki verileri arttırarak bu hasta grubundaki yaklaşımların daha güvenle uygulanmasına olanak tanıyabilir. Çalıșmamızın bazı sınırlamaları vardır. Çalışmaya dahil edilen hasta sayısı azdır, fakat bu hastaların hepsinin histopatolojik tanısı vardı ve en az altı aylık takipleri mevcuttu. Sayı olarak dezavantaj gibi görünsede, bu durum verilerimizin güvenilirliği arttırmaktadır.

Tüm limitasyolara rağmen diyebilirizki, skapulada yerleşik tümör ve tümör benzeri lezyonlar sıklıkla maligndir fakat benign tutulumlar erken yaşta daha sık görülür. Tedavi seçeneği olarak ameliyatsız klinik takip, küretaj, eksizyon veya ampütasyonun gibi pekçok alternatif vardır. Daha net sonuçlar için çok merkezli prospektif çalıșmaların yapılmasını öneriyoruz.

Etik Kurul Onay Bilgisi:

Onaylayan Kurul: Uludağ Üniversitesi Tıp Fakültesi Klinik Araştırmalar Etik Kurulu

Onay Tarihi: 28 Temmuz 2021

Karar No: 2021-10/21

Fikir ve tasarım: A.E.Y.; Veri toplama ve işleme: A.E.Y.,M.S.B. Analiz ve verilerin yorumlanması: A.E.Y.,M.S.B.; Makalenin önemli bölümlerinin yazılması: A.E.Y.,M.S.B.

Destek ve Teşekkür Beyanı:

Bu makalede yer alan çalıșmalarda herhangi bir kurul tarafindan finansal destek sağlanmamıştır.

Çıar Catıșması Beyanı:

Bu makalede makale yazarlarının çıkar çatışması beyanı yoktur.

\section{Kaynaklar}

1. Blacks in MF, Benevenia J. Neoplasms of the scapula. AJR Am J Roentgenol. 2000 Jun;174(6):1729-35. DOI: 10.2214/ajr.174.6.1741729. PMID: 10845514

2. Mavrogenis AF, Mastorakos DP, Triantafyllopoulos G, Sakellariou VI, Galanis EC, Papagelopoulos PJ. Total scapulectomy and constrained reverse total shoulder reconstruction for Ewing's sarcoma. J Surg Oncol. 2009 Dec 1;100(7):611-5. DOI: 10.1002/jso.21340. PMID: 19582796.

3. Shahid M, Varshney M, Maheshwari V, Mubeen A, Siddiqui MA, Zulfiqar J, Gaur K. Ewing's sarcoma of the scapula: a rare entity. BMJ Case Rep. 2011 Mar 10;2011:bcr0220113810. DOI: 10.1136/bcr.02.2011.3810. PMID: 22701069; PMCID: PMC3063267.

4. Cleeman E, Auerbach JD, Springfield DS. Tumors of the shoulder girdle: a review of 194 cases. J Shoulder Elbow Surg. 2005 Sep-Oct;14(5):460-5. DOI: 10.1016/j.jse.2005.02.003. PMID: 16194735

5. Kaiser, C. L., Yeung, C. M., Raskin, K., Gebhardt, M. C., Anderson, M. E., \& Lozano-Calderón, S. A. (2020). Tumors of the scapula: A retrospective analysis identifying predictors of malignancy. Surgical oncology, 32, 18-22.

6. Ogose, A., Sim, F. H., O'Connor, M. I., \& Unni, K. K. (1999). Bone tumors of the coracoid process of the scapula. Clinical Orthopedics and related research, (358), 205-214.

7. Enneking W, Dunham W, Gebhardt M, Malawar M, Pritchard D. A system for the classification of skeletal resections. Chir Organi Mov. 1990;75(1 Suppl):217-40. PMID: 2249538.

8. Khan Z, Gerrish AM, Grimer RJ. An epidemiological survey of tumor or tumor-like conditions in the scapula and periscapular region. SICOT J. 2016;2:34. DOI: 10.1051/site/2016023. Epub 2016 Oct 14. PMID: 27739400; PMCID: PMC5064673.

9. Brtková, J., Nidecker, A., Zídková, H., \& Jundt, G. (1999). Tumours and tumour-like lesions of scapula. ACTA MEDICAHRADEC KRALOVE-, 42(3), 103-110.

10. Malawer, M. M., \& Sugarbaker, P. H. (2001). Musculoskeletal cancer surgery: treatment of sarcomas and allied diseases. Springer Science \& Business Media.

11. Bickels J, Wittig JC, Kollender Y, Kellar-Graney K, Meller I, Malawer MM. Limb-sparing resections of the shoulder girdle. J Am Coll Surg. 2002 Apr;194(4):422-35. DOI: 10.1016/s10727515(02)01124-9. PMID: 11949748.

12. Xie L, X D T, Yang RL, Guo W. Interscapulothoracic resection of tumors of the shoulder with a note on reconstruction. Bone Joint J. 2014 May;96-B(5):684-90. DOI: 10.1302/0301620X.96B5.32241. PMID: 24788506.

13. Kumar VP, Satku SK, Mitra AK, Pho RW. Function following limb salvage for primary tumors of the shoulder girdle. 10 patients followed 4 (1-11) years. Acta Orthop Scand. 1994 Feb;65(1):55-61. DOI: 10.3109/17453679408993719. PMID: 8154285 . 